\title{
THE EFFECTIVENESS OF HAND MASSAGE THERAPY IN REDUCING PAIN INTENSITY AMONG PATIENTS WITH POST-LAPARATOMY SURGERY
}

\author{
Wiwin Silpia $^{1}$, Nurhayati Nurhayati ${ }^{* *}$, Henni Febriawati ${ }^{3}$ \\ ${ }^{1,2}$ Prodi Ilmu Keperawatan, Universitas Muhammadiyah Bengkulu, Indonesia \\ ${ }^{3}$ Prodi Kesehatan Masyarakat, Universitas Muhammadiyah Bengkulu, Indonesia
}

*corresponding author: nurhayati@umb.ac.id

\begin{abstract}
The incidence of laparotomy increases gradually year by year. Based on a preliminary survey that was conducted in a public hospital in Bengkulu, it was found that there were increasing cases of laparotomy surgery within the last three years. One of the main issues reported by patients with post-laparotomy surgery is acute pain in the area of incision surgery. The aim of this study was to determine the effectiveness of hand massage therapy in reducing acute pain among postlaparotomy surgery patients. This research was a quasi-experimental study with pre-test and post-test groups. The results of this study found that the respondent's ages ranged from 20 to 40 years old (53.3\%) and most of them were male $(60 \%)$. A total of $53.3 \%$ of respondents experienced severe pain after surgery, then the pain intensity decreased to mild pain by $86.7 \%$ after being given hand massage therapy. The implication of this study was expected to be a reference for nurses in dealing with acute pain in post-surgical patients.
\end{abstract}

\section{Keywords: Acute pain, hand massage, laparatomy}

\section{PENDAHULUAN}

Kasus penyakit dengan tindakan pembedahan menempati urutan ke-11 dari 50 penyakit di rumah sakit se-Indonesia dengan persentase $12.8 \%$, dan $32 \%$ diantaranya merupakan jenis bedah laparatomi (Rahmayati et al, 2018). Bedah laparatomi merupakan salah satu prosedur pembedahan mayor dengan melakukan penyayatan pada lapisan dinding abdomen yang mengalami masalah seperti perdarahan, perforasi, kanker, dan obtruksi pada area adomen. Adapun masalah yang seringkali muncul pada post operasi laparatomi adalah nyeri pada area bedah, terbatasnya lingkup gerak sendi, serta resiko infeksi (Ditya et al, 2016; Nurhayati et al, 2019). Dari beberapa masalah tersebut yang paling sering dikeluhkan pasien adalah nyeri. Nyeri pada laparatomi merupakan nyeri akut yang memiliki permulaan cepat dan berlangsung dalam waktu singkat yang terjadi karena adanya luka insisi bekas pembedahan yang menyebabkan tubuh menghasilkan mediator- mediator kimia nyeri diantaranya histamin, bradikinin, serotonin,

Jurnal Vokasi Keperawatan (JVK) Volume 4 No 1 Bulan Juni Tahun 2021

Program Study of Nursing Universitas Bengkulu

http ://ejournal.unib.ac.id/index.php/JurnalVokasiKeperawatan 
dan prostaglandin (Edi et al, 2020; Nurhayati et al, 2020). Sensasi nyeri mulai terasa sebelum kesadaran pasien kembali penuh dan semakin meningkat seiring dengan berkurangnya pengaruh anestesi. Nyeri pada laparatomi sering ditemukan dalam tingkat nyeri berat dan sedang karena rusaknya integumen, jaringan otot, vaskular dan menimbulkan efek nyeri yang lebih lama pada masa pemulihan (Rahmayati., Hardiansy, R., Nurhayati, 2018).

Manajemen nyeri merupakan salah satu cara yang digunakan dibidang kesehatan untuk mengurangi nyeri. Manajemen nyeri dilakukan dengan tujuan untuk meningkatkan mobilisasi dini, menurunkan risiko komplikasi, memperpendek lama hari rawat dan mengurangi mordibitas (Ditya et al, 2016; Nurhayati, 2019). Metode pereda nyeri nonfarmakologis merupakan tindakan mandiri perawat untuk mengurangi intensitas nyeri sampai dengan tingkat yang dapat ditoleransi oleh pasien. Sekarang telah banyak dikembangkan intervensi keperawatan yang dilakukan untuk mengurangi intensitas nyeri pasca operasi, seperti teknik rileksasi dan massage. Teknik rileksasi dapat memberikan rasa nyaman dan rileks pada pasien, dan massage bertujuan menghasilkan respon rileksasi serta massage berdampak positif untuk mengurangi nyeri (Amelia \& Saputri, 2020).

Pada nyeri post operasi laparatomi, tindakan nonfarmakologi yang efektif adalah massage. Dengan massage perawat bisa lebih komunikatif dengan pasien, sertadengan dilakukannya massage pada pasien post operasi laparatomi dapat merangsang keluarnya hormon endomorfin sehingga bisa memberikan efek tenang bagi pasien (Damayanti \& Wiyono, 2019). Adapun jenis massage yang digunakan pada pasien post operasi abdomen adalah slow stroke back massage dengan hand massage. Hand massage adalah memberikan stimulsi di bawah jaringan kulit di daerah tangan dengan mmberikan rasa nyaman dan dilakukan selama 10 menit (Fitri et al, 2018). Pada hand massage juga terdapat titik jantung yang dapat melancarkan sirkulasi darah. Pada post operasi laparatomi memerlukan sirkulasi darah yang adekuat untuk mempercepat penyembuhan luka pasca operasi sehingga dapat mengurangi nyeri. Selain itu dalam pemberian terapi ini tidak perlu menggunakan alat khusus yang membutuhkan biaya besar sehingga terapi ini dapat diberikan pada klien dengan strata ekonomi apapun (Fadilah \& Astuti, 2016). Meskipun terapi hand massage bukan merupakan pengganti untuk obat- obatan tapi tindakan tersebut diperlukan untuk mempersingkat episode nyeri yang berlangsung beberapa detik atau menit (Fadilah., Astuti., Santy, 2016).

Jurnal Vokasi Keperawatan (JVK) Volume 4 No 1 Bulan Juni Tahun 2021 
Berdasarkan survey awal yang dilakukan pneliti di salah satu rumah sakit rujukan di Kota Bengkulu didapatkan bahwa pasien yang mendapatkan tindakan pembedahan laparatomi mengalami peningkatan pada tiga tahun terakhir dengan total kasus sebanyak 511 orang. Saat dilakukan interview terhadap 5 paisen, seluruh pasien mempunyai keluhan utama yang sama yakni nyeri pada area luka post bedah. Pasien juga mengatakan teknik yang telah diajarkan perawat untuk meredakan nyeri yakni teknik relaksasai napas dalam. Berdasarkan fenomena yang terjadi di lapangan, maka peneliti tertarik untuk meneliti pengaruh terapi hand massage terhadap penurunan intensitas nyeri post operasi laparatomi.

\section{METODE}

Penelitian ini merupakan penelitian kuantitatif dengan metode quasy-experimental design dengan pre-test dan post-test group. Penelitian ini melibatkan 15 responden yang sedang menjalani rawat inap di salah satu rumah sakit rujukan di Kota Brengkulu. Teknik pengambilan sampel yang digunakan yakni purposive sampling. Kriteria inklusi responden meliputi; pasien dengan post bedah laparatomi di hari pertama, pasien komunikatif dan sadar penuh, dan pasien mengalami nyeri pasca bedah. Sedangkan kriteria ekslusinya adalah pasien dengan fraktur pada tangan. Intensitas nyeri pada penelitian ini diukur menggunakan Numeric Rating Scale (NRS) dengan interpretasi skala 0 (tidak nyeri), 1-3 (nyeri ringan), 4-6 (nyeri sedang), 7-9 (nyeri berat), dan 10 (nyeri berat tidak terkontrol).

Intervensi yang diberikan pada penelitian ini adalah terapi hand massage dengan terapis yang sudah tersertifikasi. Terapi ini menstimulasi jaringan dibawah kulit melalui pijatan atau sentuhan dan tekanan lembut pada jari-jari dan telapak tangan. Teknik pijat yang dilakukan berupa teknik friction dan squeezing. Adapun prosedurnya sebagai berikut; 1) Usap kedua tangan pasien dengan air hangat menggunakan wash lap agar rileks, 2) Hangatkan kedua telapak tangan terapis menggunakan minyak zaitun dengan cara menggosok-gosokkan kedua telapak tangan sebelum melakukan pijatan, 3) Gunakan teknik friction (gerusan) pada area antara ibu jari dan jari telunjuk, kemudian dilanjutkan pada telapak tangan pasien, 4) Lakukan teknik squeezing (meremas) dengan menekan secara lembut menggunakan ibu jari terapis pada setiap jari pasien dari pangkal ke ujung jari. Ulangi prosedur yang sama pada masing-masing tangan hingga durasi 10 menit. lakukan terapi ini selama 3 hari berturut-turut. Peneliti melakukan pengukuran intensitas nyeri pada responden setiap sebelum dan sesudah pemberian terapi hand

Jurnal Vokasi Keperawatan (JVK) Volume 4 No 1 Bulan Juni Tahun 2021 
massage menggunakan NRS. Setelah pelaksanaan intervensi selesai, data dianalisis menggunakan uji t-test.

\section{HASIL}

Table 1. Karakteristik responden $(n=15)$

\begin{tabular}{|c|c|c|}
\hline Karakteristik & $\mathbf{n}$ & $\%$ \\
\hline \multicolumn{3}{|l|}{ Umur } \\
\hline $20-40$ & 8 & 53.3 \\
\hline $41-60$ & 6 & 40 \\
\hline$>60$ & 1 & 6.7 \\
\hline \multicolumn{3}{|l|}{ Jenis Kelamin } \\
\hline Laki-laki & 9 & 60 \\
\hline Perempuan & 6 & 40 \\
\hline
\end{tabular}

Pada penelitian ini ditemukan bahwa mayoritas responden adalah laki-laki (60\%) dengan rentang usia antara 20-40 tahun (53.3\%).

Table 2. Intensitas Nyeri Sebelum dan Sesudah Terapi Hand Massage $(n=15)$

\begin{tabular}{lcc}
\hline \multicolumn{1}{c}{ Intensitas Nyeri } & $\mathbf{n}$ & $\mathbf{\%}$ \\
\hline Pre-test & 7 & \\
$\quad$ Nyeri sedang & 8 & 46.7 \\
Nyeri berat & & 53.3 \\
Post-test & 2 & 13.3 \\
$\quad$ Tidak nyeri & 13 & 86.7 \\
$\quad$ Nyeri ringan & & \\
\hline
\end{tabular}

Pada hasil distribusi frekuensi ditemukan bahwa 53.3\% responden mengalami nyeri berat sebelum diberikan terapi hand massage. Kemudian $86 . \%$ responden mengalami nyeri ringan setelah diberikan terapi hand massage.

Tabel 3. Pengaruh Terapi Hand Massage tehadap Penurunan Nyeri Post Bedah Laparatomi $(n=15)$

\begin{tabular}{cccc}
\hline Intensitas Nyeri & range & Mean \pm SD & p value \\
\hline Pre-test & $6-7$ & $6.40 \pm .828$ & .000 \\
Post-test & $1-2$ & $1.53 \pm .915$ & .000 \\
\hline
\end{tabular}

Pada hasil analisa bivariat ditemukan bahwa terapi hand massage efektif menurunkan intensitas nyeri pasien post bedah laparatomi dari 6.40 pada saat pre-test menjadi 1.53 pada saat post-test dengan nilai $p$-value $0.000(<.05)$ yang bermakna ada pengaruh terapi hand massage terhadap penurunan intensitas nyeri post bedah laparatomi. 


\section{PEMBAHASAN}

Berdasarkan hasil penelitian ini, sebelum diberikan terapi hand massage mayoritas responden mengalami nyeri berat dengan skala 7-9. Temuan ini sejalan dengan penelitian yang dilakukan oleh Nurhayati et al. (2019) yang menyatakan bahwa masalah yang kerapkali muncul pada post bedah laparatomi adalah nyeri pada area luka bedah. Nurhayati et al. (2020) menemukan bahwa intensitas nyeri post bedah laparatomi yang sering dilaporkan pasien yakni pada skala nyeri berat akibat rusaknya integumen kulit, jaringan otot dan vaskuler yang dapat berdampak pada lamanya masa pemulihan pasien. Nyeri pada pasien dengan post bedah laparatomi termasuk dalam kategori nyeri akut yang memiliki permulaan cepat dan berlangsung dalam waktu singkat. Nyeri ini dirasakan pada area luka insisi pembedahan pada abdomen akibat tubuh menghasilkan mediator-mediator kimia nyeri seperti histamin, serotonin, bradikinin dan prostaglandin.

Pada hasil penelitian ini, mayoritas responden melaporkan intensitas nyeri berat sebelum diberikan terapi hand massage, yang kemudian intensitas nyeri tersebut mengalami penurunan setelah diberikan terapi hand massage dengan skala ringan (NRS 1-3). Hasil penelitian ini sejalan dengan teori yang dikemukakan Amelia dan Saputri (2020) yang menjelaskan bahwa terapi hand massage mampu menghasilkan respon relaksasi yang berdampak positif dalam mengurangi nyeri. Hand massage merupakan salah satu terapi massage yang bdapat digunakan pada pasien dengan nyeri post bedah laparatomi. Terapi hand massage ini memberikan stimulus di bawah jaringan kulit di daerah tangan melalui sentuhan dan tekanan lembut untuk memberikan rasa nyaman.

Selanjutnya, pada hasil analisis bivariat pada penelitian ini didapatkan bahwa terdapat pengaruh terapi hand massage terhadap penurunan intensitas nyeri post bedah laparatomi. Hasil penelitian ini sejalan dengan penelitian Fadilah dan Astuti (2016) yang menemukan bahwa terapi hand massage memberikan pengaruh terhadap penurunan skala nyeri pada pasien dengan kanker. Arkley et al. (2008) menemukan bahwa massage yang dilakukan pada telapak tangan pasien selama 10 menit dapat memberikan rasa nyaman dan relaksasi. Selain itu juga dalam penelitian yang dilakukan oleh Damayanti (2019) juga menemukan efektivitas hand massage terhadap respon fisiologis dan intensitas nyeri pada pasien laparatomi memiliki pengaruh yang yang signifikan terhadap penurunan intensitas nyeri.

Jurnal Vokasi Keperawatan (JVK) Volume 4 No 1 Bulan Juni Tahun 2021

Program Study of Nursing Universitas Bengkulu

http ://ejournal.unib.ac.id/index.php/JurnalVokasiKeperawatan 


\section{SIMPULAN DAN SARAN}

Pada hasil penelitian ini dapat disimpulkan bahwa, frekuensi nyeri responden sebelum diberikan terapi hand massage rata-rata berada pada intensitas nyeri berat (53.3\%). Sebaliknya, intensitas nyeri menjadi nyeri ringan (86.7\%) setelah responden diberikan terapi hand massage. Pada hasil analisis bivariat ditemukan bahwa ada pengaruh yang signifikan terhadap penurunan intensitas nyeri setelah pemberian terapi hand massage pada responden. Berdasarkan hasil penelitian ini diharapkan kepada petugas pelayanan kesehatan terutama perawat agar dapat memberikan terapi hand massage ini sebagai salah satu terapi non-farmakologis dalam upaya perawatan pasien post bedah dengan masalah nyeri akut.

\section{DAFTAR RUJUKAN}

Amelia, W., \& Saputri, D. M. A. (2020). EFEKTIFITAS HAND MASSAGE TERHADAP SKALA NYERI PADA PASIEN POST OPERASI LAPARATOMI DI RS. DR. REKSODIWIRYO PADANG. Jurnal Kesehatan MIDWINERSLION, 5(1).

Astutik, P., \& Kurlinawati, E. (2017). Pengaruh Relaksasi Genggam Jari Terhadap Penurunan Nyeri Pada Pasien Post Sectio Caesarea. STRADA Jurnal Ilmiah Kesehatan, 6(2), 30-37.

Damayanti, R. T., \& Wiyono, J. (2019). DIFFERENCES PAIN INTENSITY BETWEEN BACK MASSAGE THERAPY AND FINGER HOLD RELAXATION IN PATIEN POST LAPARATOMY. Jurnal Keperawatan Terapan (E-Journal), 5(1), 10-21.

Ditya, W., Zahari, A., \& Afriwardi, A. (2016). Hubungan Mobilisasi Dini dengan Proses Penyembuhan Luka pada Pasien Pasca Laparatomi di Bangsal Bedah Pria dan Wanita RSUP Dr. M. Djamil Padang. Jurnal Kesehatan Andalas, 5(3).

Darmawan, A. A., \& Rihiantoro, T. (2018). Pengetahuan, Sikap dan Perilaku Mobilisasi Dini Pasien Post Operasi Laparatomi. Jurnal Ilmiah Keperawatan Sai Betik, 13(1), 110-117.

Edi Saputra, P., Misbah, S. R., \& Bau, A. S. (2020). INTERVENSI TERAPI MASSAGE TERHADAP TINGKAT NYERI PADA PASIEN POST OPERASI LAPARATOMI (Doctoral dissertation, Poltekkes Kemenkes Kendari). 
Fadilah, P. N., \& Astuti, P. (2016). Pengaruh teknik relaksasi hand massage terhadap nyeri pada pasien kanker payudara di yayasan kanker indonesia surabaya. Journal of Health Sciences, 9(2).

Meihartati, T., \& Sulistyorini, C. (2018). EFEKTIVITAS SLOW STROKE BACK MASSAGE TERHADAP NYERI PERINEUM DERAJAT 2 PADA IBU NIFAS 2 JAM POST PARTUM. Jurnal Medika: Karya Ilmiah Kesehatan, 3(2), 65-71.

Nurhayati Nurhayati BN, M. N. S. (2019). The Quality of Discharge Teaching Perceived by Surgical Nurses Working in Public Hospitals of Indonesia. International Journal of Caring Sciences, 12(1), 100-106.

Nurhayati, N., \& Madsiri, M. (2019). Managing acute pain after abdominal surgery: examples from practice. Gastrointestinal Nursing, 17(8), 20-25.

Nurhayati, N., Songwathana, P., \& Vachprasit, R. (2019). Surgical patients' experiences of readiness for hospital discharge and perceived quality of discharge teaching in acute care hospitals. Journal of clinical nursing, 28(9-10), 1728-1736.

Nurhayati, N., \& Madsiri, M. (2020). Managing acute pain after abdominal surgery: examples from practice. Journal of Prescribing Practice, 2(2), 78-83.

Rahmayati, E., Al Asbana, Z., \& Aprina, A. (2018). Faktor-Faktor yang Berhubungan dengan Lama Perawatan Pasien Pasca Operasi di Ruang Rawat Inap Bedah Rumah Sakit. Jurnal Ilmiah Keperawatan Sai Betik, 13(2), 195-202. 